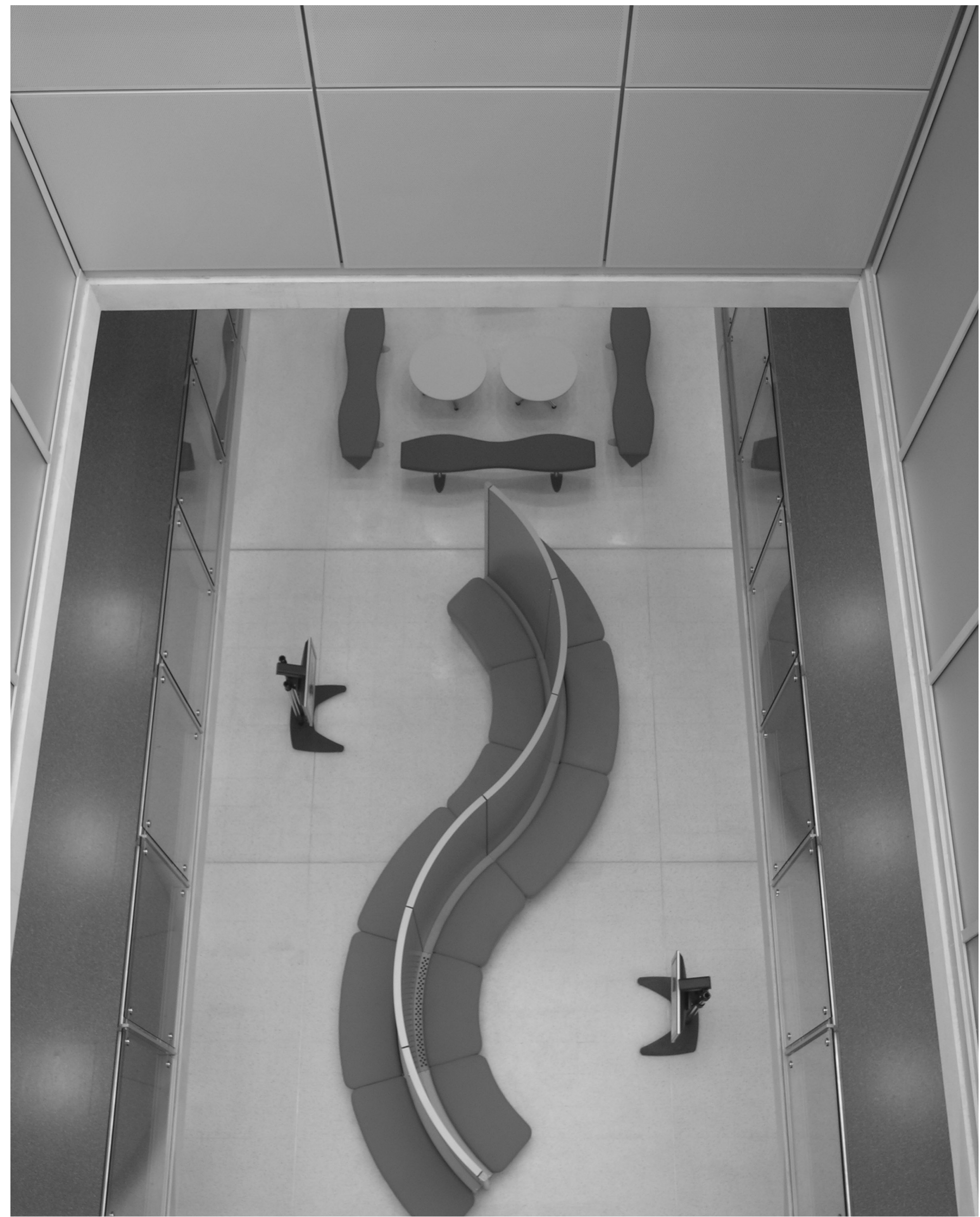


A R T I S T, $\mathrm{S}$ NOT T

\section{The Teleporter Zone: Interactive Media Arts in the Healthcare Context}

A B S T R A C T

$T_{\text {he }}$ recent development and implementation of The Teleporter Zone, a permanent interactive art installation commissioned by Guy's and St Thomas' Charity for the new Evelina Children's Hospital in London. The article places the production and conception of this installation in the context of the author's research in telematic and telepresent art over the past 15 years, alongside current research reports on the effects and influences of the arts on healthcare. The author also draws upon personal experiences in order to provide practical insights into the objectives and outcomes of this work in the healthcare context. enhancement of patient recovery. However, many of these studies concentrate on the influence of sound and music, with the remainder focusing on literature, poetry and twodimensional visual arts. The review concludes by recommending that new-media art forms be integrated into and evaluated within the healthcare culture [2]. In response to the Arts Council report, this paper presents and discusses the aims and perceived outcomes of my interactive media art installation The Teleporter Zone, created for the Evelina Children's Hospital in London in September 2005.

\section{INSTALLATION DESCRIPTION}

Commissioned by Guy's and St Thomas' Charity, The Teleporter Zone is the first interactive telematic video installation to have been developed for a U.K. hospital. The Teleporter Zone is situated on the ground floor of the hospital (Fig. 1). It provides patients and their friends and family members with a chance to interact with and experience a telematic art installation that transports their awareness from the confines of the hospital waiting area to a variety of imaginary virtual worlds.

The installation consists of a 6-meter S-shaped wall (see Article Frontispiece) concealing a row of blue seats on each side, with a videoconference connection between them. The video cameras and screens face the seats on each side of the curved wall to capture, combine and present the separate participants in the same telepresent image, as if they were sitting together in the same alcove area.

The two cameras are identically angled and mounted above LCD video screens in matching positions, 2 meters from the blue seats, on both sides of the wall. The live images are output to a system of chroma-key video mixers and a DVD player

Paul Sermon (artist), The University of Salford, Research Centre for Art \& Desig Centenary Building, Peru Street, Salford, Greater Manchester, M3 6EQ, U.K. E-mail: <p.sermon@salford.ac.uk>.

Article Frontispiece. The Teleporter Zone, 2005, an interactive art installation located in the outpatient waiting area at the Evelina Children's Hospital, London. () Paul Sermon. Photo (C) Paul Tyagi.) Viewed from the first-floor atrium. (see Fig. 2) hidden underneath the central seating area. These two camera images are brought togethe by extracting the blue areas of the video image and combining them with a third computer-generated background scene provided by the DVD player. The final composited image consists of a computer-generated background, a live camera middle ground and a live foreground image, which is simultaneously output to both LCD video screens.

The 2-meter height of the dividing wall conceals children's actual presence on either side of the installation, making it possible for them to communicate and interact with each other only via the telepresent screen in front of them. The deliberate absence of audio communication encourages the children to explore new modes of telepresent interaction and dialogue within computer-animated background scenes that suggest the content of their communication and relocate the interacting children to entirely new telepresent environments.

\section{EVELINA HOSPITAL}

The Teleporter Zone is one of five permanent artworks incorporated within the outpatient waiting area of the new hospital.

Fig. 1. The Teleporter Zone, 2005. (@ Paul Sermon. Photo @ Paul Tyagi.) The Evelina Children's Hospital, London.

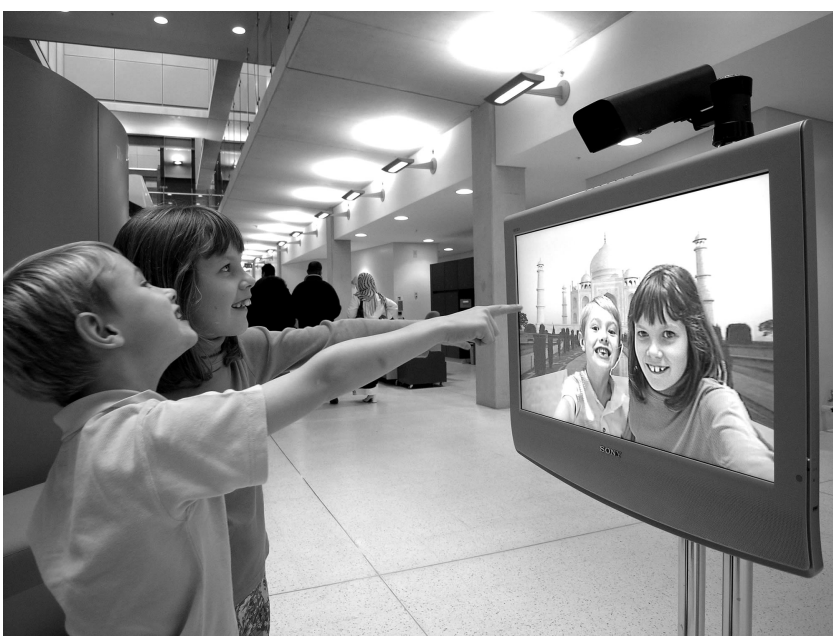




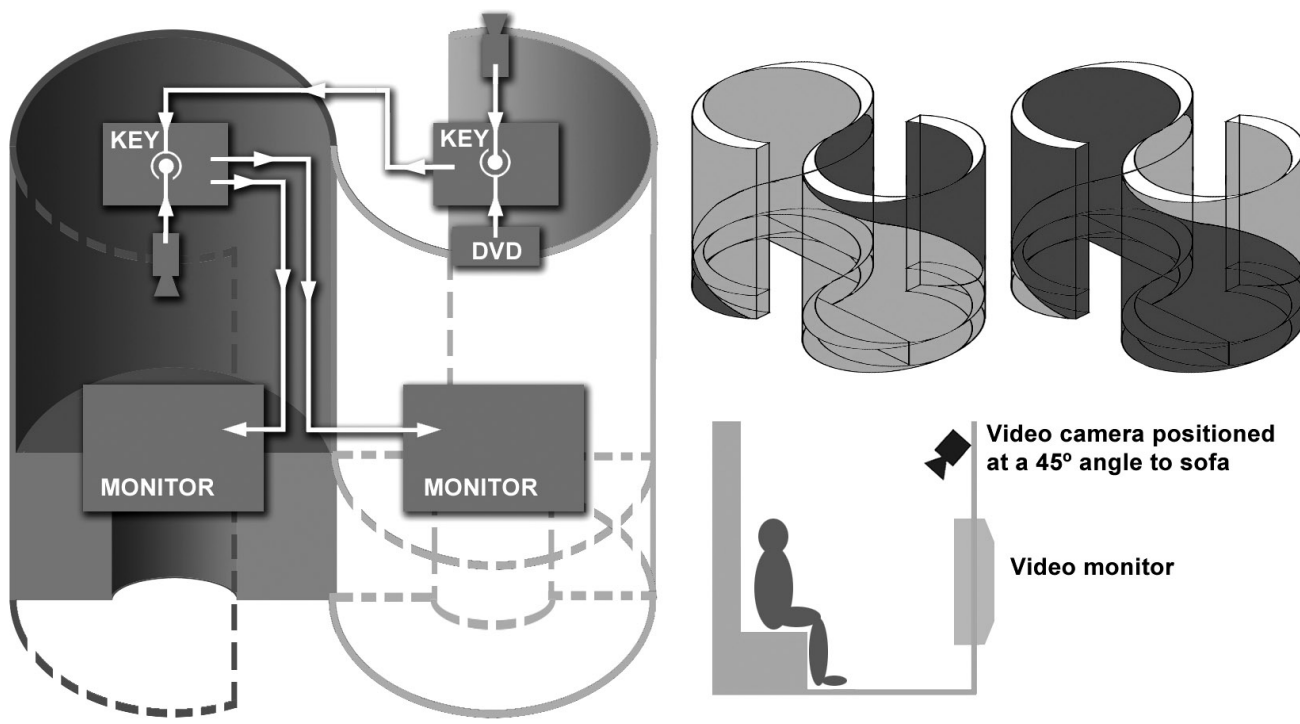

Fig. 2. The Teleporter Zone, 2005. (๑ Paul Sermon) Initial concept proposal diagrams.

The area occupies a large atrium space located directly beyond the main entrance and hospital reception. The Teleporter Zone is the very first interactive installation that visitors encounter in the space, followed by the second of the larger artworks, the Starslide helterskelter designed and constructed by sculptor Liliane Lijn [3] (see Color Plate F). These two large-scale installations intentionally offer alternative modes of interaction that provide both able and disabled children with both physical and mental stimulation. The Evelina Hospital's guiding principles were conceived by the U.K.-based healthcare strategists and consultants Rawlinson Kelly Whittlestone [4], and the building was designed by Hopkins Architects. This hospital was short-listed for the 2006 RIBA Sterling Architecture Prize [5] and has been proclaimed as one of the U.K.'s most innovative National Health Service projects.

To quote an appreciation,

The new Evelina Children's Hospital has been designed around the needs of children and their families. Its underlying philosophy is to create "a hospital that does not feel like a hospital," housing a gallery and performance space, a café and hospital school [6].

Based on this philosophy, The Teleporter Zone was designed to encourage outpatients to subconsciously relocate themselves to a different time and space, helping to remove their thoughts from the confines of the waiting area and consequently reduce the apparent time spent waiting. The installation functions simultaneously as a seated waiting area (Fig. 3) and an interactive installation. Visitors often do not realize that the seats located along both sides of the curved wall are actually part of the installation until sitting down and becoming aware of their combined presences on monitors facing the seats. The integration of the installation into the hospital surroundings is an intentional feature, developed in collaboration with the architects from the early stages of the project, incorporating the blue color scheme and design of the furniture throughout the ground floor of the building. This assimilation with the hospital environment ensures diverse interpretations and audience interactions beyond those of a gallery exhibit. Through its physical location and attraction, The Teleporter Zone has now become the central meeting point in the large waiting area, and the majority of nurses and support staff have begun to use the site as a location to announce appointments and escort patients through to the surgery.

\section{CONCEPTUAL BACKGROUND}

The conceptual thinking behind this installation is based on the development of shared telepresent virtual environments [7], made possible by the relay of live video images between two sites, combining audience participants within the same telepresent installation. My work in the field of telematic arts explores the emergence of user-determined narrative between remote participants who are brought together within a shared telepresent space. Through the use of live chroma-keying and videoconferencing techniques, these divided audience participants enter a video installation and initially presume that they are entering a passive space — sitting, standing or some- times lying within it. Their presence within the space is recorded live on video camera and combined in real time via a chroma-key video mixer with an identical camera view of another participant in an identical installation space through the replacement of a blue or green backdrop in one image with the image of the other. The two spaces, which can be any geographical distance apart, are brought together via a videoconference connection.

This is essentially how all my installation projects function, but what is most surprising for the intended viewers is that they themselves form an integral part of these telematic experiments, which simply would not function without their presence and participation within them. Audience participants rapidly become performers, or at best actors within these spaces, by observing their bodies within a telepresent space represented on selfview video monitors in front of them. User/actors ascend a rapid learning curve and begin to control and choreograph their human avatar representations of themselves in a new telematic space, in combination with other physically remote role-playing users. My main intention is to allow my audience to view and experience my work in both passive and active roles-drawing very different experiences and initial conclusions from them. While in the passive viewing mode, the audience is observing the public in what often appears to be a well-rehearsed piece of drama confidently played out by actors. Once audience participants enter this space, they immediately represent two dynamic performer roles. Their conscious role is as controllers, or puppeteers, of their own avatar performers, but 


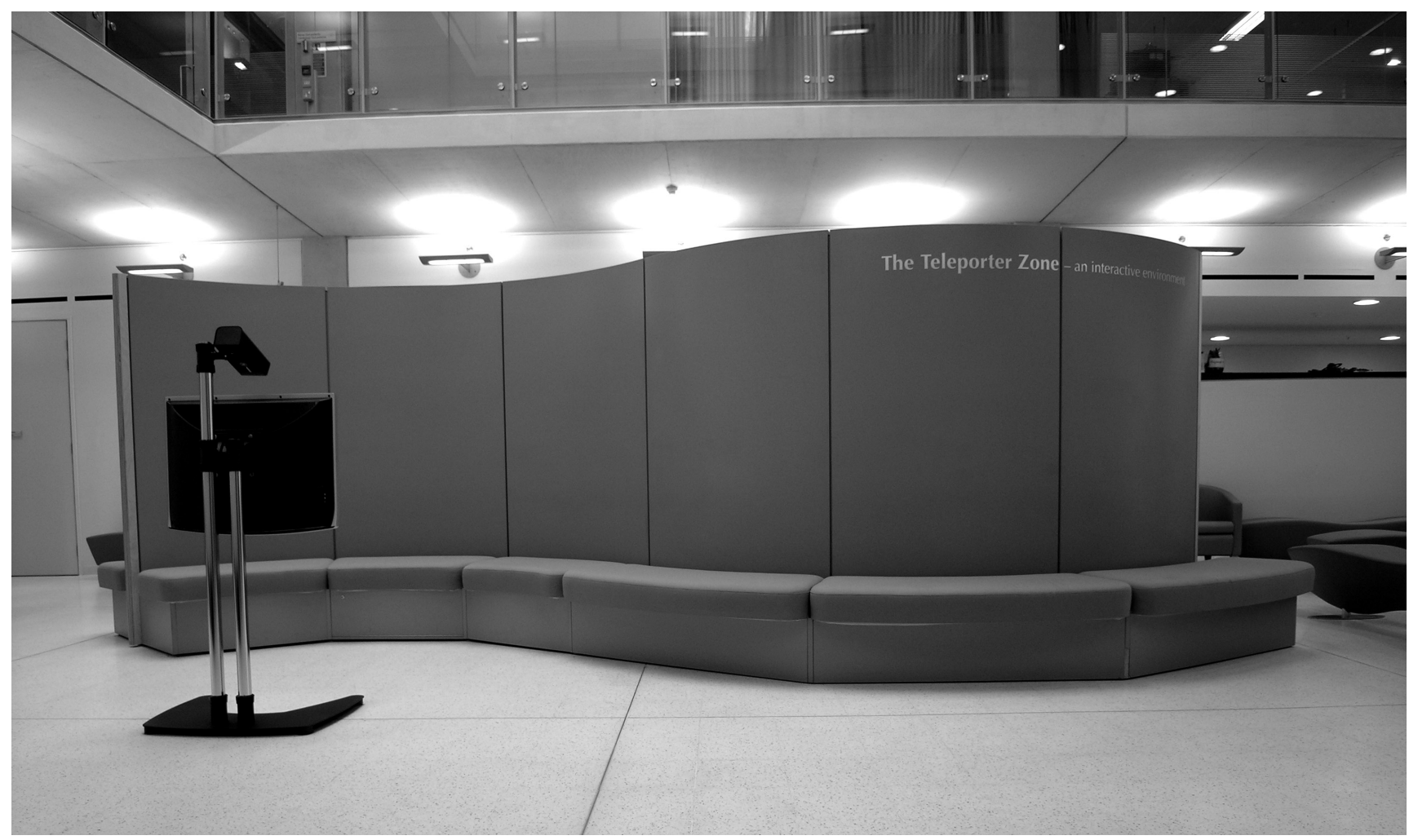

Fig. 3. The Teleporter Zone, 2005. (@ Paul Sermon. Photo $\odot$ Paul Tyagi.) Additional outpatient seating provided by the installation.

they are unaware of their secondary performing role presented to the off-camera members of the audience, who are themselves awaiting the next available slot on the telematic stage, soon to be sharing in this split dynamic. The narrative that unfolds here would appear to be determined by the user on and off camera. What is essential in such experiments, however, is the architecture of the installation. As an artist I am both designer of the environment and director of the narrative, which I determine through the social and cultural context in which I choose to play out these telepresent encounters. This technique has been used successfully in a variety of installations using tables [8], sofas [9] and beds [10] as telematic interfaces.

One of the key features of this work, and of the context of the outpatient waiting area, has been children's compelling desire to become telepresent performers "onstage" in front of themselves. After entering the installation, the participants become completely uninhibited by the public surroundings, as if they were themselves no longer present in the space. This phenomenon creates a physical sense of telepresence in the participant that Margaret Morse exposes as the far-from-explored field of human relations that have become inflected with and transformed by technology [11]. Moreover, in the same way that Lacan proposed that the human psyche is constructed in the mirror, as if onstage in front of oneself [12], I suggest that the construction of a telematic identity is taking place on the telepresent stage, and it is through these interactive environments and their user-determined narratives that we become consciously more receptive to the performer role we adopt in new social and cultural contexts. As we slip back and forth between the roles of performer and viewer, we continually return to Lacan's mirror stage: "He experiences in play the relation between the movements assumed in the image and the reflected environment, and between this virtual complex and the reality it reduplicates-the child's own body, and the persons and things around him" [13].

This situation is effortlessly entered into by young patients at the Evelina Children's Hospital. Watching a child's first reaction to The Teleporter Zone is a revelation that the performer onstage is an exact replica of the controller in the audience, so that one becomes the voyeur of one's own spectacle.

\section{HealthCare Objectives}

The Staricoff Arts Council report makes a number of references to qualitative research undertaken in the healthcare sector that suggests the arts play a significant role in aiding patient recovery and reducing anxiety [14]. However, these conclusions are often drawn from a wide range of medical conditions in a variety of different healthcare contexts; an accurate comparative study of specific positive effects of the arts on patient recuperation remains to be conducted. Yet there is a common humanistic acceptance that the arts have an important role to play in this context, and based on extensive patient observation and consultation the importance of the arts has been recognized and embraced in the contemporary hospital environment. The Guy's and St Thomas' Arts Programme is central to this belief, and its aims for the artwork's commission addressed the question of how and in what ways The Teleporter Zone could further enhance visitors' hospital experience through its potential to:

- Reduce perceived waiting time.

- Reduce anxiety.

- Build confidence.

- Encourage inventiveness.

- Engage all children regardless of age/ gender/ethnicity/disability.

- Help caregivers/parents.

- Support hospital staff.

- Aid recuperation.

Having understood the aims of this commission and the background research into the arts and healthcare, I 
could clearly foresee how the interactive telematic art installation could take patients a step further into the conscious realm of their imaginations in order to achieve these objectives. My experience of exhibiting an installation in the U.K. Millennium Dome in 2000 using a very similar concept showed that children became totally absorbed in their own interactive performances without having to be prompted about what to do or think, often spending far longer in the installation than the Millennium Dome exhibitors anticipated or wanted. However, when I received the original brief for this commission, much of my thinking and motivation was unavoidably drawn from my own experiences as a child. Although it was some 30 years ago, the image of the doctor's surgery waiting room remains a vivid memory that continues to haunt me to this day when entering a hospital; it was a dark, silent Tudor-style room with wooden wheel-back chairs along the walls, a small marble cemetery statue of a praying angel and a single gloomy image of the Virgin Mary looking down in pity on me. For me, The Teleporter Zone had to embody the utter antithesis of this psychological trauma I had experienced as a child.

\section{OUTCOMES AND CONCLUSION}

The original concept, as pictured in Fig. 2 , proposed a more secluded area for the seating in each alcove of the S-shaped structure. However, unlike in a normal gallery situation, the hospital could not provide continuous invigilation, and a more open structure was chosen in order to allow monitoring of the installation from afar. Moreover, the hospital environment presented many other difficulties, such as systems maintenance, which is simply not provided, and a high level of health and safety concerns. Therefore, an annual service agreement was made that also provided me the opportunity to receive an update from the hospital staff on how the installation continues to be used, giving me useful references for possible future work of this kind. One of the most significant results of this relation- ship so far has been the discovery of how the virtual scenes, provided on DVD and mapped into the background of the seated children, are vital to the kinds of interactive narratives that the children develop. Each sequence lasts approximately 2 minutes and enables the children to invent short stories through role-playing and interaction according to the computer-generated surroundings. The initial set of backgrounds included a variety of settings: a pirate ship, an airplane, a spaceship, the thrones of a king and queen (Fig. 4), the ocean, the clouds, and a beach. I have since noticed that familiar nonfictional locations also encourage adult family members and caregivers to participate; as a result, I have added backgrounds added that include scenes of the Pyramids, the North Pole, the Taj Mahal, etc., in order to widen the installation's use and audience. This simple method of evaluation and upgrade is one I intend to continue throughout my annual visits and the life span of the work.

The context of a children's hospital

Fig. 4. The Teleporter Zone, 2005. (๔ Paul Sermon. Photo @ Paul Tyagi.) A virtual computer-generated background.

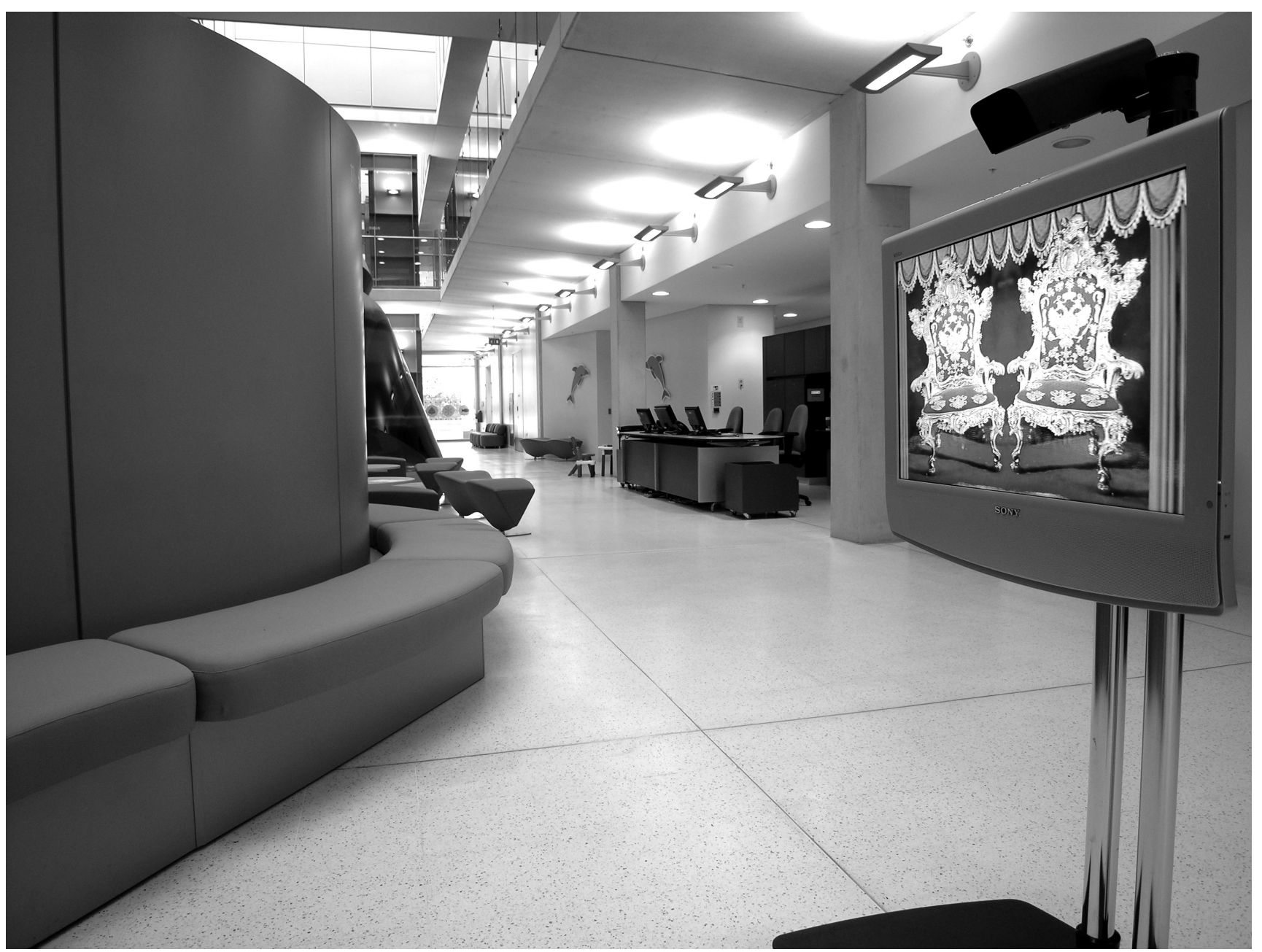


and its outpatient waiting area has been one of the most influential and important aspects of The Teleporter Zone's development. Childhood experiences and memories of a hospital or day surgery remain throughout an individual's life. As adults, we understand that tensing up at the sight of a needle is obviously not the best preparation for an injection, but it is a very difficult reaction to resist, as it is so deeply embedded within our psyches. While it will continue to be difficult to attribute a patient's recuperation directly to the experience of The Teleporter Zone, hospital staff have already informed me of the installation's success in attracting a wide range of children and of their inventiveness in using the installation, indicating that The Teleporter Zone is doing what it was intended to do and ultimately distracting them from their pending surgery appointments. I am hopeful and confident that these childhood experiences will continue to alleviate the traumatic experiences associated with the hospital visit. For me, this is the single most important aspect of The Teleporter Zone, and I hope that its effect carries on into patients' adult lives, adding a sense and memory of enjoyment and fascination to the hospital visit.

\section{References and Notes}

1. Rosalia L. Staricoff, "Arts in Health: A Review of Medical Literature," Research Report-36, Arts Council England (2004).

2. Staricoff [1] p. 32.

3. See Liliane Lijn, "Starslide: A Symbiosis of Form and Function," Leonardo 38, No. 5, 405-406 (2005)

4. <www.rkw-uk.com>

5. $<$ www.architecture.com/go/Architecture/Also/ Awards_5399.html>.

6. <www.nursingjobsinlondon.com/about/new_ evelina.htm>.

7. My telematic art installations exhibited from 1992 to 2007 can be found at <www.paulsermon.org $>$.

8. My 1997 videoconference installation The Tables Turned combined audiences from Ars Electronica Linz and ZKM Karlsruhe at the same telepresent table: <www.paulsermon.org/table/>.

9. Telematic Vision connected audiences sitting on blue sofas watching themselves on television as combined telepresent performers at ZKM Karlsruhe in 1993: <www.paulsermon.org/vision/>.

10. Telematic Dreaming, an ISDN installation, combined remote participants on the same telepresen bed at Telegalleria Finland in 1992: <www.pau sermon.org/dream/>.

11. Margaret Morse, Software/Hardware/Artware (Ostfildern, Germany: Cantz-Verlag, 2000).

12. Jacques Lacan, "The Mirror Stage," in Jacques Lacan, Écrits, (Paris: Éditions du Seuil, 1966).
13. Jacques Lacan, "The Mirror Stage," in Jacques Lacan, Écrits: A Selection (London: Routledge, 1989) p. 2.

14. Staricoff [1] p. 14

\section{Glossary}

chroma-key-The removal of a color from one image to reveal another image behind it. This technique is also referred to as "green-screen" and "bluescreen" and commonly used for weather forecast broadcasts.

telematics-The integrated use of telecommunications and informatics, the science of sending, receiving and storing information via telecommunication devices.

teleportation-The movement of objects or elementary particles from one place to another, more or less instantaneously, without their travel through space.

telepresence-A set of technologies that allow one to feel as if one were present, to give the appearance that one is present, or to have an effect at a location other than one's true location.

Manuscript received 4 December 2006.

Paul Sermon is currently professor of Creative Technology at the University of Salford in Manchester, U.K., and a practicing artist working primarily within the research field of immersive and expanded telematic environments. 
Copyright of Leonardo is the property of MIT Press and its content may not be copied or emailed to multiple sites or posted to a listserv without the copyright holder's express written permission. However, users may print, download, or email articles for individual use. 